\title{
The role of iron on the degradation and mineralization of organic compounds using conventional Fenton and photo-Fenton processes
}

\author{
Daphne Hermosilla ， Manuel Cortijo , C.P. Huang \\ Departamento de Ingeniería Quimica, Facultad de Ciencias Químicas, Universidad Complutense de Madiz, Ciudad universitaria s/n, 28040 Madid, Span \\ U.D. Operaciones Básicas, Departamento de Ingenietía Forestai, E.T.S.I. Montes, Universidad Politécnica de Madrid, Avda. Ramiro de Maeztli s/n, 28040 Madrid, Spain \\ Department of Civil and Environmental Engineering, 352C DuPont Hall, university of Delaware, Newark, DE 19716, USA
}

Keywords:

Fenton

Photo-Fenton

Iron complex

Phenol

Nitrophenol

Acetic acid

Oxalic acid

EDTA

Advanced oxidation processes

\begin{abstract}
A B S T R A C T
The role of iron on the degradation of different organic compounds, differing in their structure (aliphatic versus aromatic) and iron complex formation capacity, by conventional and photo-Fenton processes was investigated. Results show that these chemical characteristics can affect the degree of treatment in terms of COD and TOC removals. While aromatics exhibited a fast and great reduction in the COD by the conventional Fenton process, aliphatic compounds, apart from acetic acid, required the presence of $U V$ light to enhance treatment results. EDTA and oxalic acid responded very positively to UV irradiation in both COD removal and mineralization, reaching the highest values showed by aromatics; and results depended on the intensity of the $U V$ light applied. Phenol and 4-nitrophenol responded favourably to $U V$ irradiation in terms of mineralization and slightly in COD removal. Reductions in the COD were almost total ( $95.99 \%)$, while only an $80 \%$ of reduction in the TOC was achieved, for the best photo-Fenton treatment of oxalic acid, phenol and nitrophenol. $60 \% \mathrm{COD}$ and $40 \%$ TOC removals were achieved correspondingly in the case of EDTA. Acetic acid showed almost no mineralization and low COD removal ( $\approx 20 \%$ ) when treated by a conventional Fenton process; and did not enhanced results when assisting the treatment with $\mathrm{UV}$ light. Photo-regeneration of ferrous ion and photo-decarboxylation of iron carboxylates are assessed in the framework of these results.
\end{abstract}

\section{Introduction}

Advanced oxidation processes ( $A O P$ s) are excellent alternatives for the treatment of recalcitrant organic compounds that are resistant to biological and/or classical physico-chemical methods; and probably they will represent one of the best options for wastewater treatment in the near future [1]. Chemical oxidation is the preferred choice for the treatment of bio-refractory wastewaters, when economically and technologically viable, as it involves the total or partial destruction of contaminants to carbon dioxide and water or to other products that may be less hazardous to the environment or may be easier to degrade by other technologies. That is, it is not limited to the simple transference of compounds from the solution to another phase. AOPs are defined as the oxidation processes that produce enough quantity of hydroxyl radicals to effect wastewater treatment [2]. The hydroxyl radical is one of the most reactive free radicals. It is twice as reactive as chlorine and its oxidation potential is between that of atomic oxygen and fluorine [3]. Moreover, it has been demonstrated that hydroxyl radicals are the main reactive species governing the degradation reactions of organic pollutants [4].

The catalysis of hydrogen peroxide by ferrous ion (i.e., Fenton's reagent) is one of the most common AOPs. In 1894, Fenton [5] described how this reagent showed great oxidizing capacity to many organic molecules. Briefly, and as reported by many authors [6-9], Ferrous ion initiates and catalyses the decomposition of $\mathrm{H}_{2} \mathrm{O}_{2}$ resulting in the generation of hydroxyl radicals that will attack organic compounds, producing organic radicals that can be further transformed through different pathways, among which ferric to ferrous ion reduction is an example. Furthermore, hydroxyl radicals may be partially scavenged by the oxidation of ferrous to ferric ion.

Fenton process has been reported to be successful when applied to the treatment of several organic chemicals [10-19]. mainly among the aromatics, and wastewaters like textile dye industry effluent [20], pulp industry effluent [21] and landfill leachate [7,22]. Despite its highly oxidative efficiency and environmental friendly nature, the application of Fenton's reagent to wastewater treatment is limited by the final production of ferric iron sludge, which may add additional waste disposal cost. In addition, some chemicals, such as acetic acid, oxalic acid and chloroform are not supposed to be oxidized readily by the Fenton's reagent $[3,23]$. In order to 
deal with these problems, modifications of the Fenton process have been proposed, such as the combined application of electricity (electro-Fenton) and/or UV light (photo-Fenton). Particularly, the combination of UV radiation with Fenton's reagent appears to be the most promising alternative because it allows the reduction of ferric to ferrous iron $[11,24]$, i.e:

$\mathrm{Fe}\left(\mathrm{ll}\left[\mathrm{OH}^{2+}+h v \rightarrow \mathrm{Fe}(\mathrm{I})+\mathrm{OH}^{*}\right.\right.$

and the photo-decarboxylation of ferric carboxylates $[11,25]$, i.e.:

$\mathrm{Fe}(\mathrm{IlI})\left(\mathrm{RCO}_{2}\right)^{2+}+h v \rightarrow \mathrm{Fe}(\mathrm{II})+\mathrm{CO}_{2}+\mathrm{R}^{\bullet}$

$\mathrm{R}^{\bullet}+\mathrm{O}_{2} \rightarrow \mathrm{RO}_{2} \rightarrow$ Products

As shown in the above equations, not only the degradation efficiency may be improved, but also some additional organic compounds (carboxylates) may be treated by the photo-Fenton process. Several studies have reported the successful photo-Fenton treatment of various organic chemicals (e.g. pheno] $[1,11,26]$, nitrophenols [17], p-chlorophenol [27], EDTA [18] and acetic acid [23]). herbicides [28], and wastewaters (e.g. landfill leachate [22] and paper mill wastewaters [29]), showing that the treatment efficiency was better than when applying the conventional Fenton process without the participation of UV light. The influence of the supplied UV power in the efficiency of the photo-Fenton process has not been addressed sufficiently. Sinha et al., 2007 [23], reported this particular in the photo-Fenton treatment of strong acetic acid liquors. Results of this essay are limited to degradation percentages, as well as it is reported in most of the studies reporting these and other advanced oxidation treatments such as ozonation, photocatalysis with $\mathrm{TiO}_{2}$, and several combinations of them.

Despite the prolific bibliography reporting the treatment of bio-refractory chemicals (e.g. aromatics and EDTA) by different advanced oxidation technologies, very few studies show mineralization figures and none of them reduction of the COD in the treatment of aliphatic chemicals by photo-oxidation processes. Even though oxalic and acetic acids have been identified as recalcitrant byproducts in the oxidation treatment of aromatic substances and diethylene glycol $[17,30-32]$, research on its specific treatment by Fenton like processes is limited. Apart from Sinha et al. [23], who reported the photo-Fenton treatment of strong acetic acid liquors [23], some authors have reported the electro-Fenton treatment of several carboxylic acids [33-34], an old research documented the conventional Fenton treatment of acetic acid [35], and Quici et al. [36], studied the combined heterogeneous photocatalysis and photo-Fenton treatment of high concentration oxalic acid solutions. Even though most of these acids are biodegradable and their intrinsic toxicity is relatively low [33], they are often mixed with other bio-refractory compounds in wastewaters $[23,33,36]$. Furthermore, carboxylic acids have been identified as byproducts of the degradation of these bio-refractory chemicals, such as several aromatics $[17,28,30]$. Moreover, carboxylic acids are harmful to skin and mucous membranes, and their environmental impact cannot be neglected due to their significant contribution to rainwater acidity and their capacity to complex heavy metals [33].

Some comparative studies showed that Fenton processes yield the highest degradation rates among AOPs applied to the treatment of several chemical solutions (e.g. phenol [1], diethylene glycol [31]. oxalic acid [36] and dichlorophenol [37]), but interesting cost and mineralization figures are also reported for ozonation techniques applied to aromatics [1,37]. Nevertheless, degradation and mineralization results showed by photocatalytic $\mathrm{TiO}_{2}$ treatments are comparatively very similar, although at slower rates, for several chemical solutions (e.g. phenol [1], dichlorophenol [37], nitrophenol [38], EDTA [39], or acetic acid [40]). Furthermore, photocatalytic $\mathrm{TiO}_{2}$ treatment has some advantages, as no oxidant is consumed and the catalyst can be easily removed. Particularly, the success-
Table 1

Stability constants ( $\log K: 25^{\circ} \mathrm{C}$ ) for fertous and tertic complexes formation of the studied organic chemicals.

\begin{tabular}{lclcl}
\hline Organic chemical & $\log K\left(\mathrm{Fe}^{2+}\right)$ & & $\log K\left(\mathrm{Fe}^{3+}\right)$ & \\
\hline \multirow{3}{*}{ Acetic acid } & 1.4 & $\mathrm{FeL}$ & 3.4 & $\mathrm{FeL}$ \\
& & & 6.5 & $\mathrm{FeL}_{2}$ \\
& & & 9.6 & $\mathrm{FeL}_{3}$ \\
Oxalic acid & 3.1 & $\mathrm{FeL}$ & 7.5 & $\mathrm{FeL}$ \\
& 5.2 & $\mathrm{FeL} 2$ & 1.3 .6 & $\mathrm{FeL}_{2}$ \\
& & & 18.5 & $\mathrm{FeL}$ \\
EDTA & 16.1 & FeL & 27.7 & FeL \\
& 19.3 & FeHL & 29.2 & $\mathrm{FeHL}$ \\
4-Nitrophenol & 20.4 & FeOHL & 33.8 & FeOHL \\
Phenol & & & 5.6 & $\mathrm{FeL}$ \\
\hline
\end{tabular}

L= ligand; values are taken from Martell and Smith 1989 | 43 | and Stumm and Morgail $1996|44|$.

ful photocatalytic mineralization of low concentration ( $50 \mathrm{ppm}$ ) carboxylic acids by $\mathrm{TiO}_{2}$ has been reported [40].

The major objectives of this study are: (a) the assessment of the regeneration of ferrous to ferric iron and the breakdown of iron complexes during the photo-Fenton treatment of five organic chemicals differing in their structure and iron complexes formation constants (three aliphatics: acetic acid, oxalic acid and EDTA; two aromatics: phenol and 4-nitrophenol) and (b) the comparison of the efficiencies achieved in the treatment of these chemicals by Fenton and photo-Fenton processes under equal operative conditions. The efficiency of every treatment was evaluated throughout the process in terms of chemical oxygen demand (COD) and total organic carbon (TOC). Other derived parameters as pseudo-firstorder rate constants $(k)$ in terms of TOC [17], mean oxidation number of organic carbon (MOC) [41] and partial oxidation efficiency ( $\mu_{\text {coDpartox }}$ ) [42] were also calculated. Besides covering the above range of structures and iron complexes formation constants (Table 1), these chemicals are widely present in domestic and industrial wastewaters (e.g. detergents, cleaning and decontaminating products, solvents, pesticides, and in the agro-industrial and food processing, textile, paper, pharmaceutical and metal industries) and require an effective treatment $[11,16,17,23,28,29,36,42]$.

\section{Experimental}

\subsection{Material and analytical methods}

All chemicals used in this study were obtained from MERK Darmstadt Chemical Company and PANREAC S.A. (Spain). Phenol, 4-nitrophenol, EDTA and oxalic acid, which were available in its purest form (99.99\%) and ultra-pure glacial acetic acid (99.99\%), were diluted with ultra-pure deionised water to the desired concentration less than 15 min prior to use. Stability constants for iron complexes formation of the chemicals to be treated are provided in Table $1[43,44]$. Ferrous sulphate hepta-hydrate was prepared at a concentration of $1 \mathrm{M}$ by diluting with ultra-pure dejonised water and was maintained under acidic $\mathrm{pH}$ until use. Hydrogen peroxide was obtained in its $30 \%$ (w/v) stable form. All stock solutions were stored in light-resistant Pyrex glass bottles under refrigerated conditions $(T=4 \circ \mathrm{C})$.

Chemical oxygen demand (COD) was measured by the Hach-vials colorimetric method at $600 \mathrm{~nm}$ using a Hachspectrophotometer (Hach DR/2000) according to the standard methods for the examination of water and wastewater [45]. Residual hydrogen peroxide in the solution may interfere with this $\operatorname{COD}$ analysis protocol $[46,47]$. Following the theoretical approximation provided by Kang et al. [47], we have corrected 
this interference fitting the relationship between COD and hydrogen peroxide content to a second-order polynomial equation $\left(\mathrm{DQO}\left(\mathrm{H}_{2} \mathrm{O}_{2}\right)=-0.000020\left[\mathrm{H}_{2} \mathrm{O}_{2}\right]^{2}+0.393239\left[\mathrm{H}_{2} \mathrm{O}_{2}\right] ; \quad r^{2}=99.92 \%\right.$; $p=0.0001$ ) [22]. The same chemicals and devices used in the experiments were used to build this relationship.

Total organic carbon (TOC) measurements were performed by the combustion-infrared method [45] using a Shimadzu $5000 \mathrm{~A}$ TOC-analyzer. TOC was estimated by simple subtraction of the total carbon (TC) and the inorganic carbon (IC) measured in every sample. In order to integrate the information provided by both $C O D$ and TOC, the mean oxidation number of organic carbon (MOC $=4 \cdot[1-($ COD $/ T O C)]$, considering COD and TOC in molar units) [41] and the partial oxidation efficiency of the solution ( $\mu_{\text {CODpart }}=\mathrm{COD}_{\text {partox }} /\left(\mathrm{COD}_{0}-\mathrm{COD}\right)$; where $\left.\operatorname{COD}_{\text {patt } 6 \mathrm{~K}}=\mathrm{COD} \cdot\left(\mathrm{TOC} / \mathrm{TOC}_{0}\right)-\mathrm{COD}\right)$ [42] were also evaluated along every treatment. As initial chemicals may be removed quickly leading to reaction intermediates and products, peudo-first-order rate constants $(k)$ in terms of TOC [17] were additionally calculated $\left(-k=\ln \left(\operatorname{TOC}_{T} \mathrm{TOC}_{0}\right) / t\right)$; and the presence and concentration of different organic chemicals produced in the breakdown of the treated compounds was measured by high-pressure liquid chromatography (Model HP 2100, Agilent, CA, USA).

Hydrogen peroxide content was analyzed using the titanium sulphate spectrophotometric method [48]. Soluble ferrous jon concentration ( $\left[\mathrm{Fe}^{2+}\right]$ ) was determined using the 1,10-phenanthroline colorimetric method [45]. To avoid the interference of ferric ion, ammonium fluoride was chosen as masking agent [41]. According to the standard methods [45], total soluble iron concentration was determined reducing ferric ion to ferrous ion by hydroxylamine under acidified conditions, and then, its concentration was measured as described above. Ferric ion concentration was estimated as the subtraction of ferrous ion concentration to the total iron concentration.

\subsection{Experimental procedure}

Fenton and photo-Fenton reaction conditions were chosen after an extensive literature review. The following conditions were applied in the treatments: $T=25^{\circ} \mathrm{C}+\mathrm{pH} 3.0$, initial $\left[\mathrm{Fe}^{2+}\right]=0.8 \mathrm{mM}$, initial $\left[\mathrm{H}_{2} \mathrm{O}_{2}\right]=30 \mathrm{mM}$, and an initial COD of the solution to be treated of $475 \mathrm{mgO}_{2} \mathrm{~L}^{-1}$. These values have been reported optimal for the treatment of aromatics by Fenton and photo-Fenton processes [11-13,16,17,26]. Furthermore, these values of $\mathrm{pH}$ and temperature have been widely applied as optimal for the Fenton or photo-Fenton treatment of different substances and wastewaters $[11-14,16-20,22,23,26-29]$. In order to perform proper comparisons, the same conditions of initial COD and reagents concentrations have been applied in all the treatments. All experiments were repeated three times.

Conventional Fenton experiments were carried out in bath mode with a magnetic stirring device to ensure complete mixing. The total solution volume treated was $4 \mathrm{~L}$. $\mathrm{pH}$ was continuously adjusted to $3.0 \pm 0.1$ using $1 \mathrm{~N} \mathrm{NaOH}$ or $1 \mathrm{~N} \mathrm{H}_{2} \mathrm{SO}_{4}$. $\mathrm{FeSO}_{4}$ was first added to get the designed initial $0.8 \mathrm{mM}$ ferrous ion concentration. ln order to assess the interference due to the $\mathrm{Fe}^{2+}$-complex formation with the chemical in the solution, hydrogen peroxide was secondly added, after a 5 -min delay, to the desired $30 \mathrm{mM}$ concentration level. Just before hydrogen peroxide addition (time $=0$ ), ferrous ion concentration, total iron, $C O D$, and TOC were measured in the solution. All these parameters and hydrogen peroxide concentration were determined at $10,20,30$, and 60 min after adding hydrogen peroxide.

Two different high-pressure mercury immersion lamps of 100 and 450 W nominal power from ACE-glass (product codes: 7825-30 and 7825-35) were used in the photo-Fenton treatment experiments. These lamps radiate a total power of 11.49 and $175.9 \mathrm{~W}$, respectively, from the infrared to the UV-C wavelengths. The selected UV lamp was located vertically in the centre of the same reactor used in the conventional Fenton process. These lamps were enclosed inside a quartz glass vessel to which water was circulated through in order to reduce the excessive heating. The whole assembly was covered with aluminium foil and thick black tape and was also mounted on a magnetic stirring device. Addition of chemicals, as well as the measurements of COD, TOC, total iron and reagents concentrations followed the same time schedule described above for conventional Fenton experiments. The UV lamp was switched on as hydrogen peroxide was added (time $=0$ ).

\section{Results and discussion}

The following figures show the time-course evolutions of COD, TOC, $\left[\mathrm{Fe}^{2+}\right],\left[\mathrm{Fe}^{3+}\right],\left[\mathrm{H}_{2} \mathrm{O}_{2}\right]$, mean oxidation number of organic carbon (MOC) and partial oxidation efficiency $(\mu$ conpartox $)$ throughout the treatment of the studied organic compounds (acetic acid, oxalic acid, EDTA, phenol and 4-nitrophenol) by conventional Fenton and photo-Fenton ( 100 and $450 \mathrm{~W}$ ) processes. The calculus of pseudofirst-order rate constants $(k)$ in terms of TOC is also provided for the treatment of every chemical.

Results in Fig. 1 show that conventional Fenton process was able to degrade the aromatic compounds effectively by the attack of hydroxyl radicals. The percent COD degradation by conventional Fenton process was $\approx 75-80 \%$ for both compounds, whereas it was only $\approx 20-25 \%$ for acetic acid and less than $10 \%$ for EDTA and oxalic acid. Apart from acetic acid, results showed in Fig. 1 also indicate that UV irradiation had a significant effect, particularly great regarding oxalic acid and EDTA, on the degradation of these chemicals. COD removal increased considerably and rapidly when increasing the UV light intensity in combination with the Fenton treatment of oxalic acid and, to a lesser extent, EDTA, achieving reductions in the COD of $99 \%$ and $58 \%$, respectively. UV light application showed no significant influence on removing COD from the acetic acid solution, remaining at $\approx 20-25 \%$ regardless the UV light power applied. Finally, COD removal also increased significantly upon UV irradiation from a $75 \%$ to $80 \%$ (conventional Fenton) to an almost complete reduction in the $\operatorname{COD~(96-99\% )~when~treating~}$ phenol and 4-nitrophenol.

Furthermore, both phenolic substances broke down quickly ( $<10 \mathrm{~min}$ ). In fact, HPLC measurements showed the absence of phenol and 4-nitrophenol in the treated solutions just 5 min after the reaction began, with or without UV radiation. Oxalic acid was found as the most important byproduct in the treatment of phenol; the amount of oxalic acid produced $\left(351 \mathrm{mg} \mathrm{L}^{-1}\right.$ ) was equivalent to $62 \mathrm{mgO}_{2} \mathrm{~L}^{-1} \mathrm{COD}$, which represents about half of the remaining COD. The reaction mechanism of hydroxyl radical with aromatic chemicals has been precisely described previously $[17,30,32]$. It consists of an electrophilic addition to the aromatic ring with the formation of hydroxylated radical, dihydroxycyclohexadienyl in the case of p-nitrophenol [32]. This radical may undergo different reactions according to the nature of the reaction solution. Under oxidative conditions, this radical will undergo hydroxylation reactions. Maleic acid has been also identified as one of the main byproducts yielded by Fenton degradation of phenol [30] and 4-nitrophenol [32], in addition to fumaric and oxalic acids. Our results on the decomposition of phenol by the Fenton process also agreed with these and other authors reporting carboxylic acids, such as oxalic and acetic acid, among the most important byproducts $[17,30,32,49]$.

Fig. 2 shows the evolution in time of the removal of TOC achieved by the Fenton, the $100 \mathrm{~W}$ and the $450 \mathrm{~W}$ photo-Fenton treatments of the selected chemicals. These results clearly indicate the effect of UV irradiation on the performance of the Fenton process in terms of 


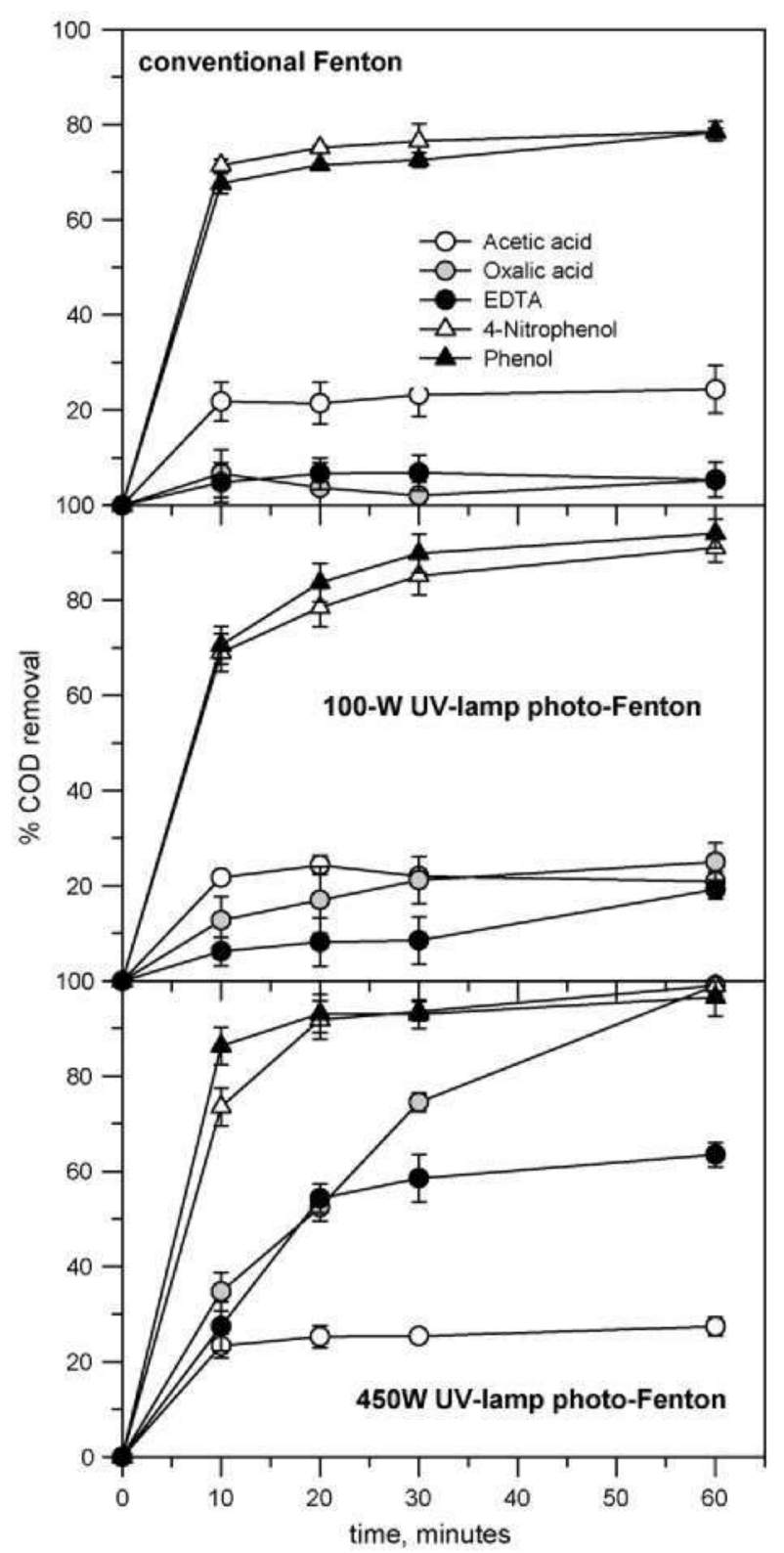

Fig. 1. Removal of $C O D$ as a function of time when treating acetic acid (- $\left.\bigcirc^{-}\right)$ oxalic acid (O), EDTA (- - ), phenol $\left(-\mathbf{\Delta}^{-}\right)$and $4-$ nitrophneol $\left(-\Delta_{-}^{-}\right)$by Fenton and photo-Fenton at 100 and 450 W UV light intensities. Experimental conditions: total solution volume $=4 \mathrm{~L} ; \mathrm{COD}=475 \mathrm{mgO}_{2} \mathrm{~L}^{-1}$ for all chemicals solutions; $T=25^{\circ} \mathrm{C} ; \mathrm{pH}$ $3.0 ;\left[\mathrm{Fe}^{2+}\right]=0.8 \mathrm{mM} ;\left[\mathrm{H}_{2} \mathrm{O}_{2}\right]=30 \mathrm{mM}$. Values are $m \pm \mathrm{sd}(n=3)$.

reduction of the TOC for all the treated compounds except for acetic acid. Particularly, while only a $\approx 20-25 \%$ TOC removal was achieved by the conventional Fenton treatment of the aromatics, this was much improved, up to a $55 \%$ and $80 \%$, when the Fenton reaction was assisted by 100 and 450 W UV lamps, respectively. Mineralization of aliphatics resulted harder. This resulted null for acetic acid in every case. Not even a $20 \%$ TOC removal was achieved for oxalic acid with the $100 \mathrm{~W}$ UV lamp. It results close to a $40 \%$ for EDTA when applying the $450 \mathrm{~W}$ photo-Fenton. The treatment of aromatics and oxalic acid by the $450 \mathrm{~W}$ photo-Fenton produced similar results in terms of reduction in the TOC $(\approx 80 \%)$. These results clearly remark the light-sensitive nature of the transformation and mineralization of EDTA, oxalic acid, phenol, 4-nitrophenol and other generated byproducts by the Fenton oxidation process (Fig. 3).

Additionally, pseudo-first-order rate constants $(k)$ in terms of TOC [17] were calculated (Table 2), for every treatment

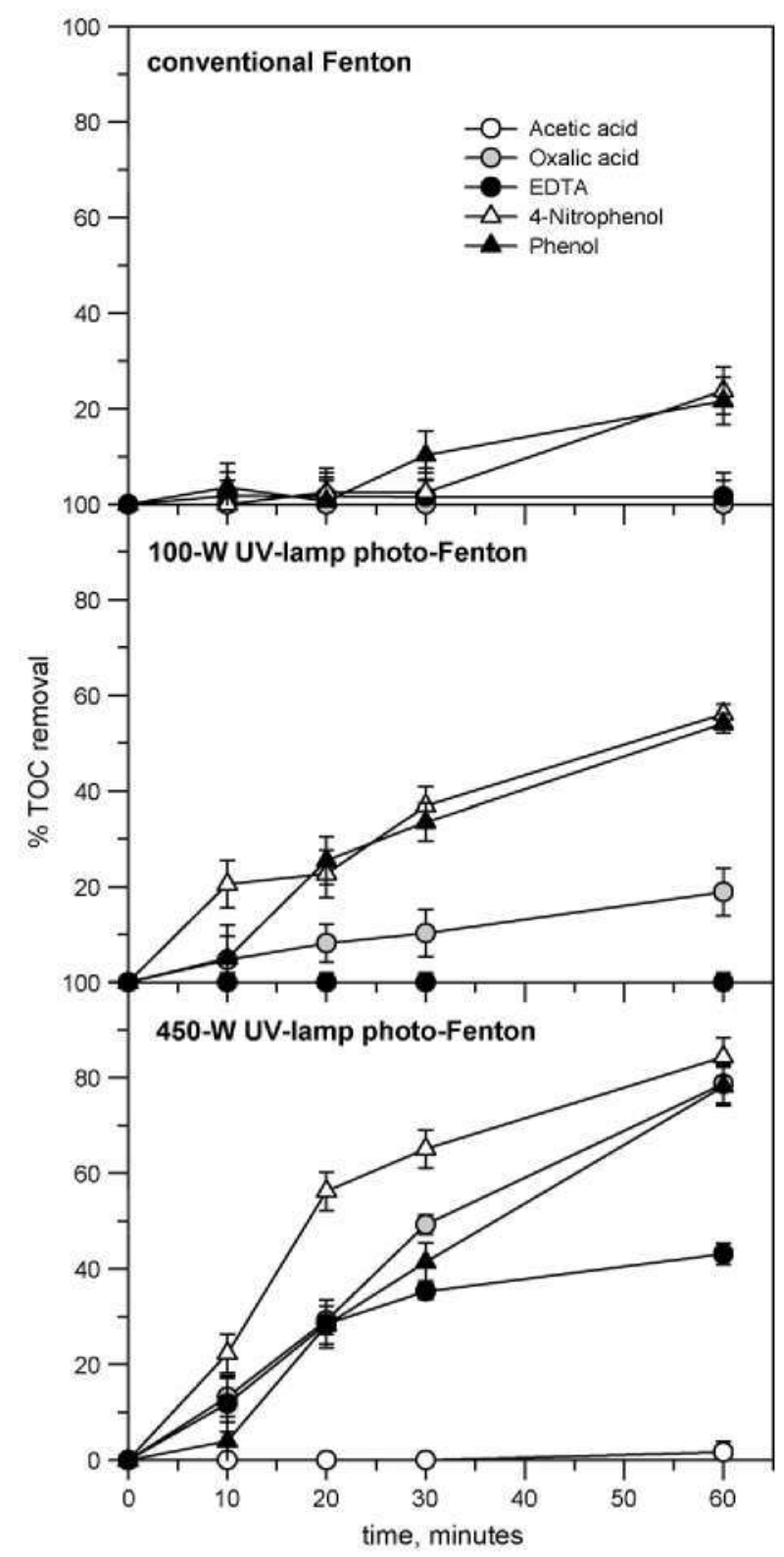

Fig. 2. Mineralization as a function of time when treating acetic acid (- - ) oxalic acid (O), EDTA (--), phenol $\left(-\mathbf{\Delta}^{-}\right)$and 4 -nitrophneol $\left(-\Delta^{-}\right)$by Fenton and photo-Fenton at 100 and $450 \mathrm{~W}$ UV light intensities. Experimental conditions: total solution volume $=4 \mathrm{~L} ; \mathrm{COD}=475 \mathrm{mgO}_{2} \mathrm{~L}^{-1}$ for all chemicals solutions; $T=25^{\circ} \mathrm{C} ; \mathrm{pH}$ $3.0 ;\left[\mathrm{Fe}^{2+}\right]=0.8 \mathrm{mM} ;\left[\mathrm{H}_{2} \mathrm{O}_{2}\right]=30 \mathrm{mM}$. Values are $m \pm \mathrm{sd}(n=3)$.

of every studied chemical, from the plots included in Fig. 3 $\left(-k=\ln \left(\mathrm{TOC} / \mathrm{TOC}_{0}\right) / t\right)$. The corresponding half-lives $\left(\tau_{1 / 2}=0.693 / k\right)$ are also provided in Table 2 . The efficiency of one treatment over another was evaluated by the ratio between the corresponding $k$ values. First of all, no results can be provided for acetic acid, neither for all the aliphatics in the conventional Fenton treatment and nor for EDTA in the $100 \mathrm{~W}$ photo-Fenton treatment because no reduction of the TOC was achieved. The achieved mineralization rates of the $100 \mathrm{~W}$ photo-Fenton treatment of phenol and nitrophenol resulted similar and even higher than the best reported by Bali et al. [26], and Kavitha and Palanivelu [17], respectively, when treating these chemicals by photo-Fenton treatments. $450 \mathrm{~W}$ photo-Fenton treatment yielded 1.63 and 2.23 times higher rates for phenol and nitrophenol, respectively. In conclusion, the application of UV radiation improved much $(\approx 4-15$ times, in the cases where this comparison can be performed) the rates of mineralization yielded 
Table 2

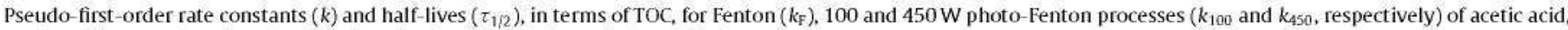
oxalic acid, EDTA, phenol and 4-nitrophenol, along with their applied-UV efficiency.

\begin{tabular}{|c|c|c|c|c|c|c|c|c|c|c|c|c|}
\hline \multirow[t]{2}{*}{ Chemical } & \multicolumn{3}{|c|}{ Fenton treatment } & \multicolumn{4}{|c|}{$100 \mathrm{~W}$ photo-Fenton treatment } & \multicolumn{5}{|c|}{$450 \mathrm{~W}$ photo-Fenton treatment } \\
\hline & $k_{\mathrm{F}}\left(\mathrm{min}^{-1}\right)$ & $r^{2}$ & $t_{1 / 2}(\mathrm{~min})$ & $k_{100}\left(\min ^{-1}\right)$ & $r^{2}$ & $t_{1 / 2}(\min )$ & $\overline{k_{100} / k_{\mathrm{F}}}$ & $k_{450}\left(\mathrm{~min}^{-1}\right)$ & $r^{2}$ & $t_{1 / 2}(\mathrm{~min})$ & $k_{450} / k_{100}$ & $k_{450} / k_{\mathrm{F}}$ \\
\hline Acetic acid & - & - & - & - & - & - & - & - & - & - & - & - \\
\hline Oxalic acid & - & - & - & 0.0075 & 0.99 & 92,4 & - & 0,0428 & 0.98 & 16.2 & 5.71 & - \\
\hline EDTA & - & - & - & - & - & - & - & 0.0243 & 0.96 & 28.5 & - & - \\
\hline Phenol & 0.0059 & 0.92 & 117.5 & 0.0244 & 0.92 & 28.4 & 4.14 & 0.0397 & 0.97 & 17.5 & 1.63 & 6.73 \\
\hline 4-Nitrophenol & 0.0043 & 0.82 & 161.2 & 0.0293 & 0.99 & 23.7 & 6.81 & 0.0654 & 0.98 & 10.6 & 2.23 & 15.21 \\
\hline
\end{tabular}

by a simple conventional Fenton treatment, particularly in the case of the studied aliphatics, where this difference turns crucial, as it turns from the null reduction in the TOC to yield interesting positive results.

Fig. 4 shows the change of $\mathrm{Fe}^{2+}$ content along the reaction time as affected by UV light. There were no $\mathrm{Fe}^{2+}$ losses before adding the hydrogen peroxide to the solution containing phenol or 4nitrophenol. In the case of acetic acid, a small amount of $\mathrm{Fe}^{2+}$ was lost. These results could be explained by the weak ferrous ion complex formation of these chemicals (Table 1). On the other hand, $\mathrm{Fe}^{2+}$ losses were great in the case of oxalic acid and almost total for EDTA, corresponding to their stronger ferrous complex formation stability constants (Table 1). Results in Fig. 4 also show the regeneration of $\mathrm{Fe}^{2+}$ species upon UV radiation. When all the hydrogen peroxide is consumed, no more $\mathrm{Fe}^{2+}$ is consumed in the catalysis of the hydroxyl radical generation from hydrogen peroxide, so its regeneration from ferric iron can be noticed (Eqs. (1) and (2)). All organics studied but acetic acid showed significant $\mathrm{Fe}^{2+}$ regeneration upon UV light irradiation because all the complexes with $\mathrm{Fe}^{2+}$ or $\mathrm{Fe}^{3+}$ (with the exception of $\mathrm{Fe}^{3+}$-acetic acid complex) can be broken by the UV light and $\mathrm{Fe}^{2+}$ can be also regenerated from $\mathrm{Fe}^{3+}$.

The decrease in $\mathrm{Fe}^{2+}$ content in the solution (Fig. 4) shows the increase in $\mathrm{Fe}^{3+}$ one (Fig. 5) in all the treatments of the aromatics and when photo-assisted Fenton was performed for aliphatics, with the exception of acetic acid; that is, an excellent mass balance of total iron is reflected. Conventional Fenton treatment led to the total loss of iron via complexation for all the aliphatics. Phenolic substances, which concentrations to produce a COD of $475 \mathrm{mgO}_{2} \mathrm{~L}^{-1}$ in the solution are comparatively low $(2.20 \mathrm{mM}$ phenol and $2.12 \mathrm{mM}$ nitrophenol) and would not form very strong iron complexes (Table 1), showed high $\mathrm{Fe}^{3+}$ contents in the solutions even when they were treated by the conventional Fenton. This may be explained by the produced regeneration of $\mathrm{Fe}^{2+}$ via reaction between intermediates or hydrogen peroxide and $\mathrm{Fe}^{3+}$ $[15,50,51]$. When the organic species form reasonable stable complexes with iron, ferrous ion regeneration can only be brought by photo-decarboxylation (Eq. (2)), which is greatly achieved in all the cases in which UV light is applied; with the exception of acetic acid, where free $\mathrm{Fe}^{3+}$ presence is almost negligible. In this case, acetic acid-Fe ${ }^{3+}$ complexes were not likely to be broken even applying the 450 W UV lamp. Hence, the regeneration to $\mathrm{Fe}^{2+}$ is impossible and then the Fenton reaction cannot progress. It should be noticed that while there is free hydrogen peroxide in the solution, iron is measured in its ferric form, as ferrous ion is quickly reduced yielding hydroxyl radicals.

Precisely, Fig. 6 shows the change of the hydrogen peroxide content in the solution as a function of time and in the presence and absence of UV light when performing the Fenton treatment to the selected chemicals. For the conventional Fenton treatment, $\mathrm{H}_{2} \mathrm{O}_{2}$ decreased rapidly in the solutions containing phenol or 4nitrophenol because the presence of free iron allows the Fenton process to progress. According to Lipczynska-kochany, Alegría et

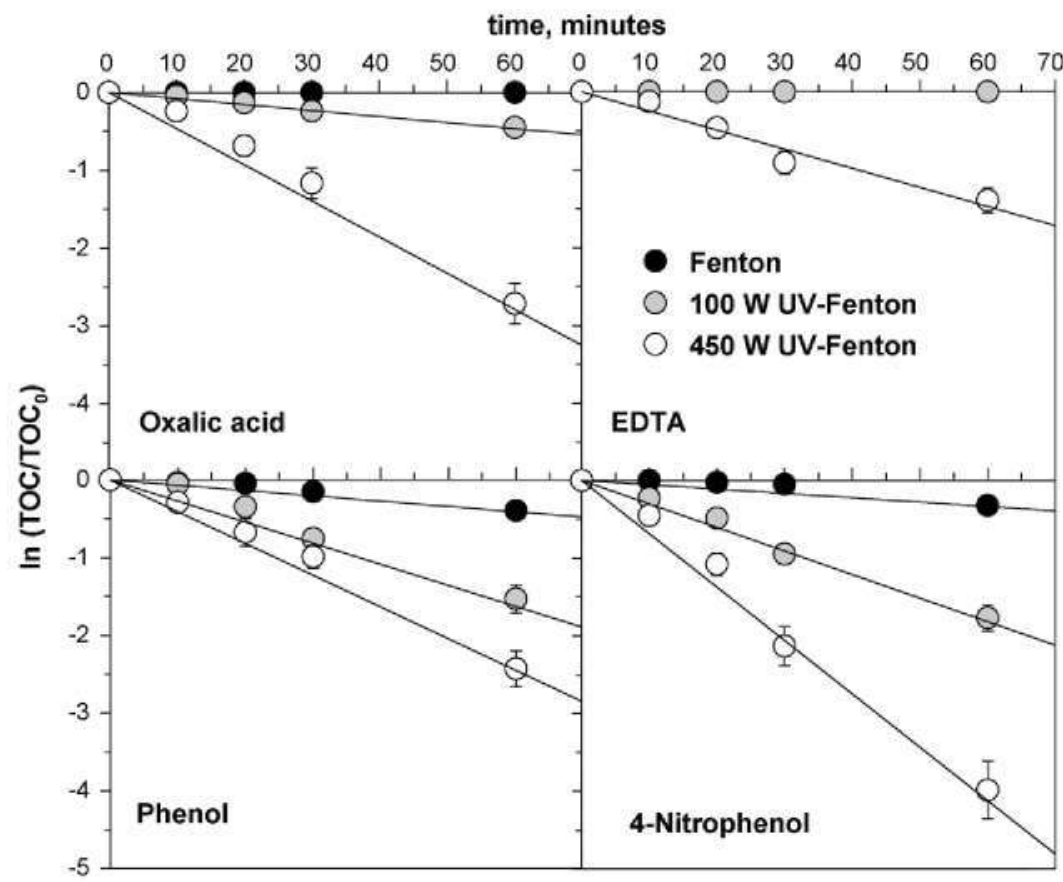

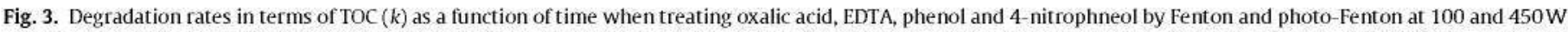

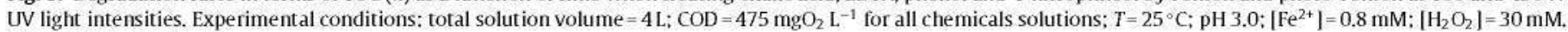
Values are $m \pm \mathrm{sd}(n=3)$. 


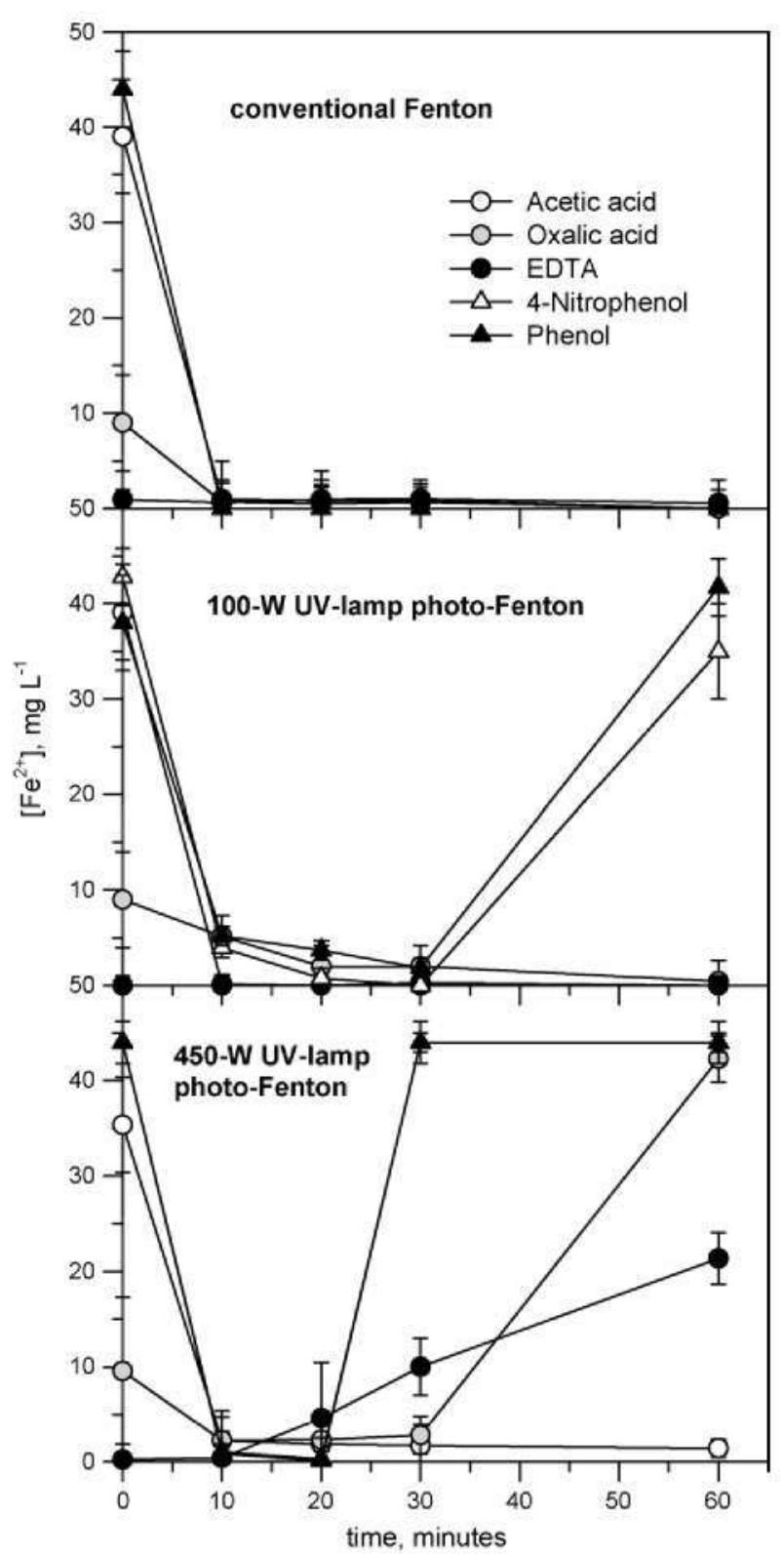

Fig.4. Change of ferrous ion concentration as a function of time whentreating acetic acid (- $\left.{ }^{-}\right)$oxalic acid (O), EDTA (- - ), phenol (- $\left.\mathbf{-}^{-}\right)$and 4-nitrophneol $\left(-\Delta^{-}\right)$by Fenton and photo-Fenton at 100 and 450 W UV light intensities. Experimental conditions: total solution volume $=4 \mathrm{~L} ; \mathrm{COD}=475 \mathrm{mgO}_{2} \mathrm{~L}^{-1}$ for all chemicals solutions; $T=25^{\circ} \mathrm{C} ; \mathrm{pH} 3.0 ;\left[\mathrm{Fe}^{2+}\right]=0.8 \mathrm{mM} ;\left[\mathrm{H}_{2} \mathrm{O}_{2}\right]=30 \mathrm{mM}$. Values are $m \pm \mathrm{sd}(n=3)$.

al., and Pignatello et al. [15,50,51], the reduction of $\mathrm{Fe}^{3+}$ to $\mathrm{Fe}^{2+}$ consuming $\mathrm{H}_{2} \mathrm{O}_{2}$ does take place, but the reaction rate is of several orders of magnitude slower than when the oxidation of $\mathrm{Fe}^{2+}$ to $\mathrm{Fe}^{3+}$ is produced in the presence of $\mathrm{H}_{2} \mathrm{O}_{2}$. It is interesting noticing that the concentration of $\mathrm{H}_{2} \mathrm{O}_{2}$ remained relatively unchanged in the solutions containing EDTA, acetic acid or oxalic acid for the conventional Fenton treatment. This can be explained by the lack of free ferrous ion presence in the solution, which is the most important $\mathrm{H}_{2} \mathrm{O}_{2}$ consumer. Particularly, in the acetic acid solution treatment, a first $\mathrm{H}_{2} \mathrm{O}_{2}$ consumption round is possible, as far as the initially added $\mathrm{Fe}^{2+}$ is not so strongly complexed than in the cases of oxalic acid and EDTA (Fig. 4); so Fenton reaction takes place. But afterwards, the generated $\mathrm{Fe}^{3+}$ must be greatly complexed with the acetic acid. This particular could be partially attributed to the relative high concentration of this chemical $(7.42 \mathrm{mM})$ needed to produce an equal COD solution to the other compounds studied in

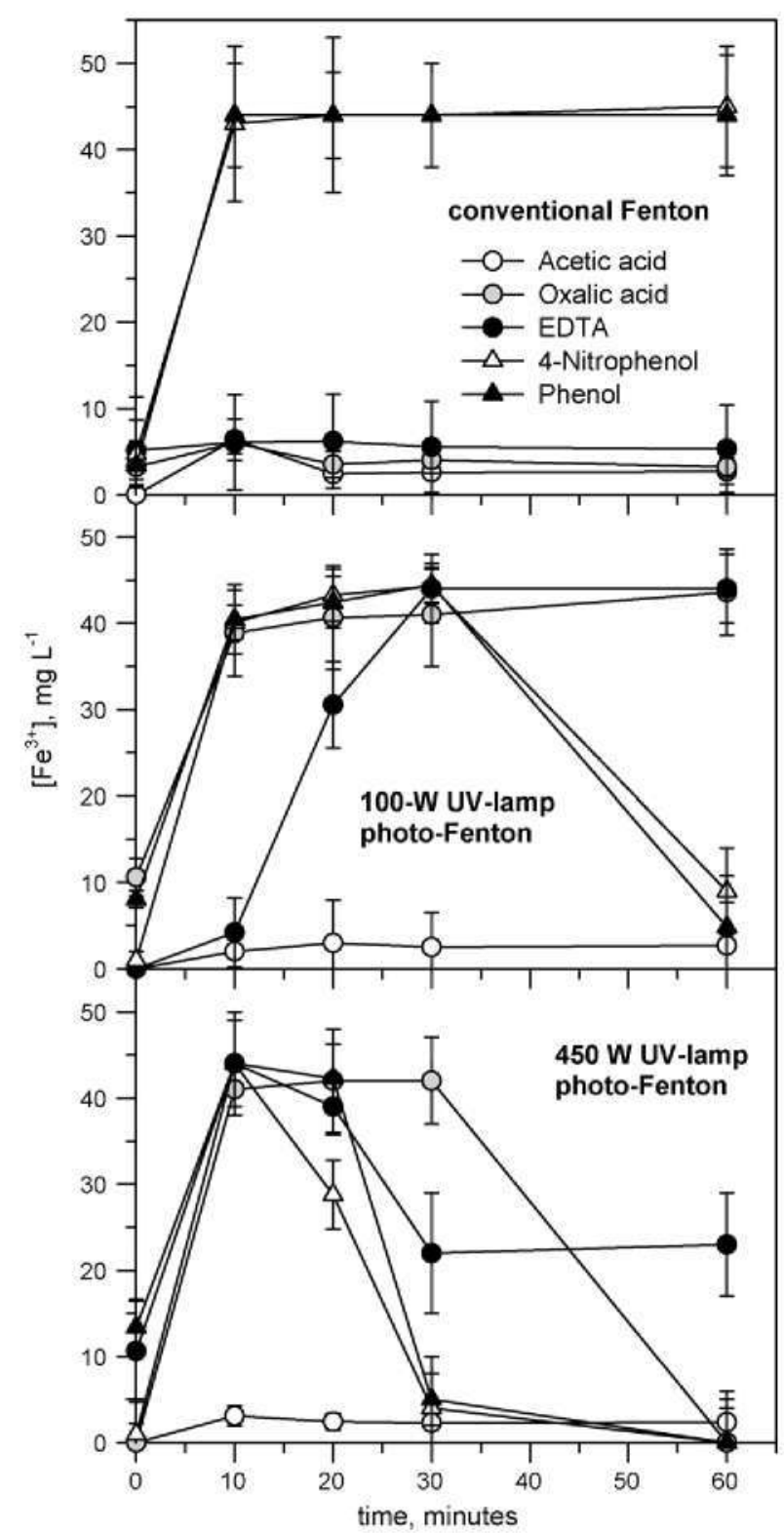

Fig. 5. Ferric ion concentration as a function of time when treating acetic acid $\left(-\mathrm{O}^{-}\right)$ oxalic acid ( $O$ ), EDTA (- - ), phenol $\left(-\mathbf{\Delta}^{-}\right)$and 4 -nitrophneol $\left(-\Delta_{-}\right)$by Fenton and photo-Fenton at 100 and $450 \mathrm{~W}$ UV light intensities. Experimental conditions: total solution volume $=4 \mathrm{~L} ; \mathrm{COD}=475 \mathrm{mgO}_{2} \mathrm{~L}^{-1}$ for all chemicals solutions; $T=25^{\circ} \mathrm{C} ; \mathrm{pH}$ $3.0 ;\left[\mathrm{Fe}^{2+}\right]=0.8 \mathrm{mM} ;\left[\mathrm{H}_{2} \mathrm{O}_{2}\right]=30 \mathrm{mM}$. Values are $m \pm s d(n=3)$.

this research. As a result, the Fenton reaction cannot take place; hence the oxidation treatment cannot further progress. If we use about 3.5 times less acetic acid $(2.12 \mathrm{mM}$, that is, the same concentration needed of 4-nitrophenol to yield $475 \mathrm{mgO}_{2} \mathrm{~L}^{-1}$ ), the results were the same than those already shown in Figs. 1 and 2 . If it is likely to be achieved, an acetic acid effective treatment by these processes requires a very much higher cost in reagents and/or energy. Finally, increasing the UV lamp power assisting Fenton process led to higher and/or faster hydrogen peroxide consumption, accordingly to the oxidation treatment results showed in terms of COD and TOC removals (Figs. 1 and 2 ).

Time-course evolutions of the mean oxidation number of organic carbon (MOC) for every treated chemical and different performed treatment are shown in Fig. 7. This parameter integrates the information from COD and TOC of the solution and it has been chosen to detect whether a change in these parameters is due to a chemical degradation process or to a physical elimination like 


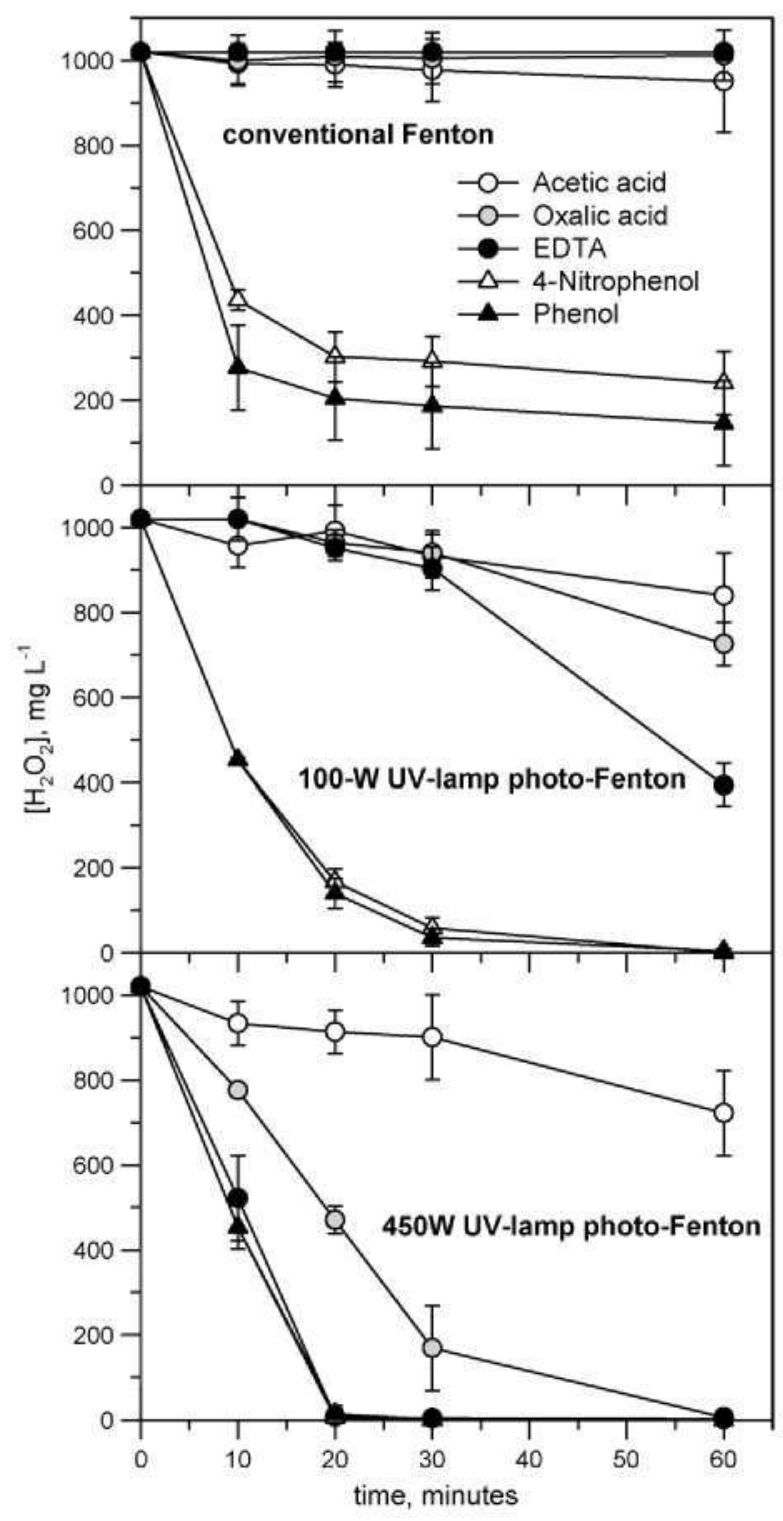

Fig. 6. Evolution of hydrogen peroxide concentration as a function of time when treating acetic acid $\left(-\mathrm{O}^{-}\right)$oxalic acid (O), EDTA (--), phenol $\left(-\mathbf{\Delta}_{-}^{-}\right)$and 4 -nitrophneol $\left(-\Delta^{-}\right)$by Fenton and photo-Fenton at 100 and 450 W UV light intensities. Experimental conditions: total solution volume $=4 \mathrm{~L} ; \mathrm{COD}=475 \mathrm{mgO}_{2} \mathrm{~L}^{-1}$ for all chemicals solutions; $T=25^{\circ} \mathrm{C} ; \mathrm{pH} 3.0 ;\left[\mathrm{Fe}^{2+}\right]=0.8 \mathrm{mM} ;\left[\mathrm{H}_{2} \mathrm{O}_{2}\right]=30 \mathrm{mM}$. Values are $m \pm s d(n=3)$.

adsorption, precipitation or stripping [41]. MOC of phenol and 4nitrophenol solutions changed to values close to those showed by oxalic acid when applying a conventional Fenton treatment; while it did not change significantly for oxalic acid and EDTA solutions. Finally, acetic acid showed identical MOC time-course evolution figures for all the treatments, that is, it will have risen from 0 to 1 after $10 \mathrm{~min}$ from the beginning of any of the performed treatments and will remain constant thereafter. When combining with a 100 W UV light treatment (photo-Fenton), the results were pretty similar but showing certain significant MOC increase for phenol, 4-nitrophenol and EDTA treatments. If the $450 \mathrm{~W}$ photo-Fenton treatment was applied, MOC increased by a whole unit when oxalic acid and EDTA were treated. Phenol and 4-nitrophenol treatment by the $450 \mathrm{~W}$ photo-Fenton led to a lower increase in the MOC, but showing a similar tendency than in the case of oxalic acid and EDTA. MOC curves of aromatics showed the same evolution reported by Vogel et al. [41] for the wet oxidation of an aqueous phenol solution;

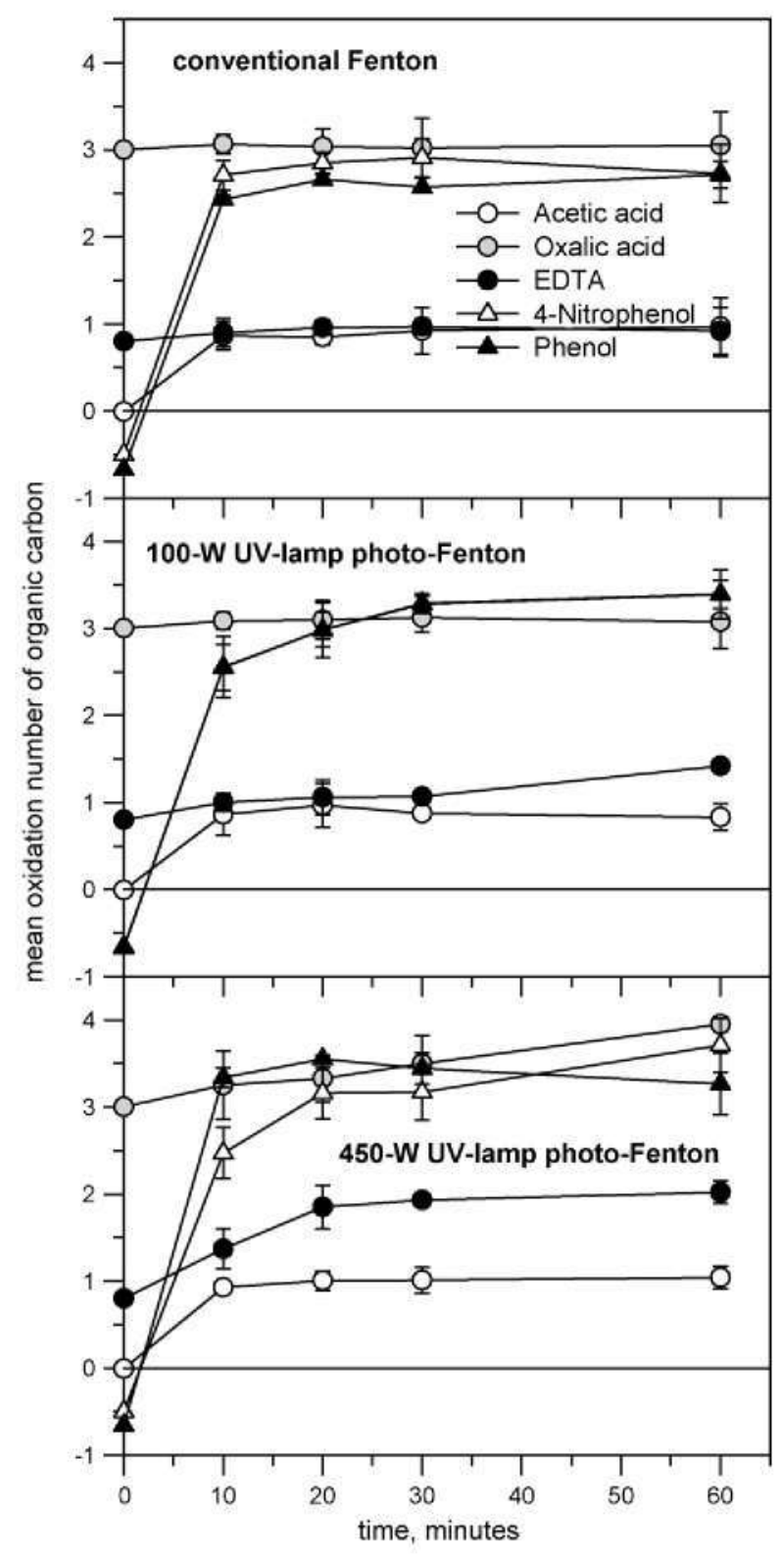

Fig. 7. Change of the mean oxidation number of organic carbon (MOC) as a func tion of reaction time when treating acetic acid (- $\left.0^{-}\right)$oxalic acid (O), EDTA (- - ), phenol $\left(-\mathbf{A}^{-}\right)$and 4-nitrophneol $\left(-\Delta_{-}\right)$by Fenton and photo-Fenton at 100 and $450 \mathrm{~W}$ UV light intensities. Experimental conditions: total solution volume $=4 \mathrm{~L}$; $\mathrm{COD}=475 \mathrm{mgO}_{2} \mathrm{~L}^{-1}$ for all chemicals solutions; $T=25^{\circ} \mathrm{C} ; \mathrm{pH} 3.0 ;\left[\mathrm{Fe}^{2+}\right]=0.8 \mathrm{mM}$; $\left[\mathrm{H}_{2} \mathrm{O}_{2}\right]=30 \mathrm{mM}$. Values are $m \pm \mathrm{sd}(n=3)$.

that is, a great MOC increase in the first 10 min of the reaction, due to the breakage of the aromatic ring yielding carboxylic acids, which led to a stationary state ( $\mathrm{MOC} \approx$ constant) derived from the compensation between the incorporation of oxygen to the molecules (increase of the MOC) and decarboxylation processes (decrease of the MOC).

A complementary way of integrating COD and TOC information along every treatment is given by the partial oxidation efficiency ( $\mu_{\text {coDpartox }}$, Fig. 8), which calculus provides a measure of the mineralization capacity of an oxidation system [42]. Partial oxidation COD $\left(C O D_{\text {partox }}\right)$ represents the percentage decrease of the COD leading to oxygenated products other than $\mathrm{CO}_{2}$ and $\mathrm{H}_{2}$ O. As shown in Fig. 2 , the conventional Fenton treatment was not able to mineralize the treated aliphatics at all, so most of the treatment efficiency was devoted to transform the initial compound in the solution to other chemicals leading to a lower integrative COD value in the solution. 


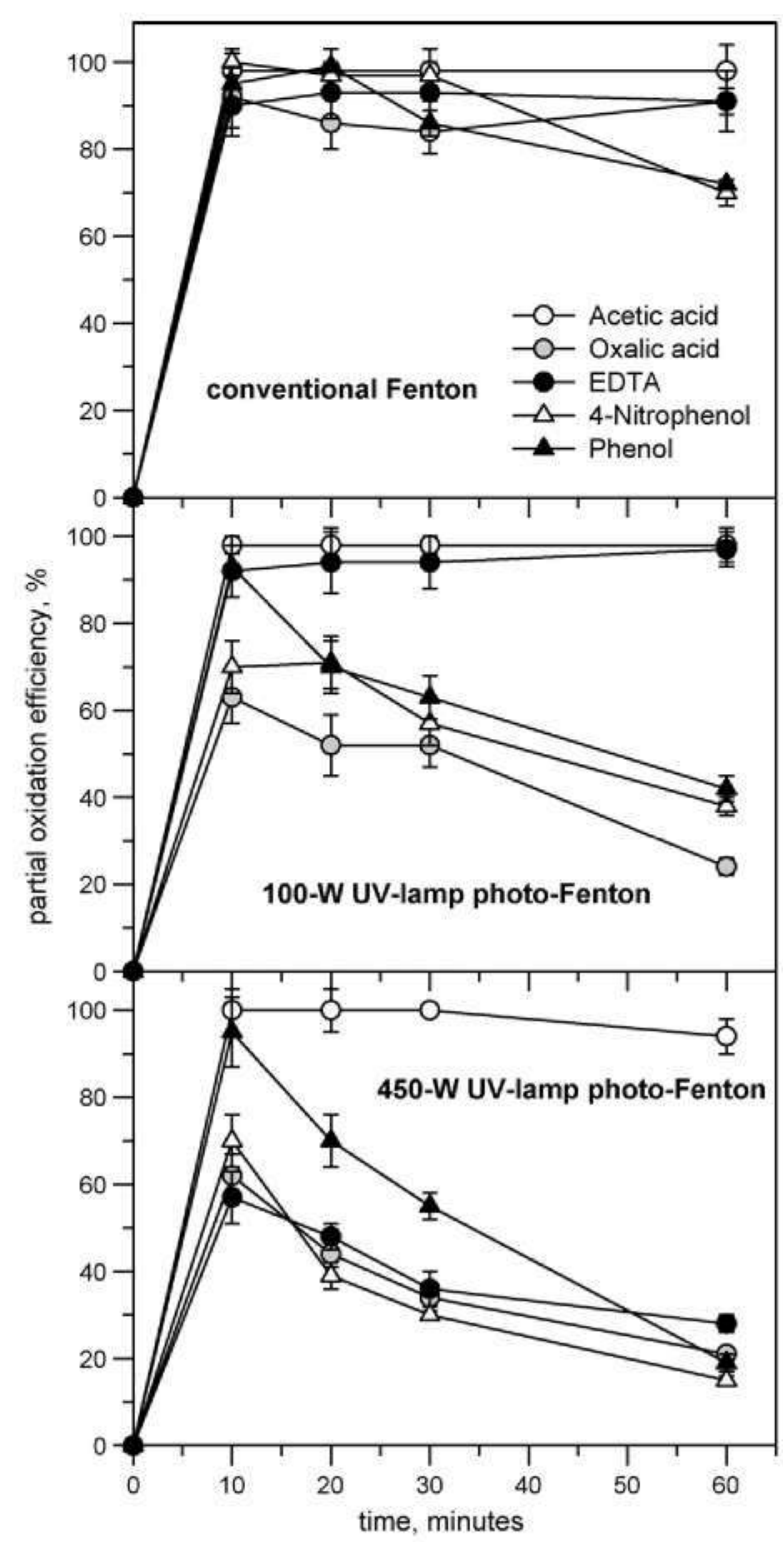

Fig. 8. Partial oxidation efficiency ( $\left.\mu_{\text {conpartox }}\right)$ as a function of time when treating acetic acid $\left(-\mathrm{O}^{-}\right)$oxalic acid $\left(\mathrm{O}^{-}\right)$, EDTA $(--)$, phenol $\left(-\boldsymbol{\Delta}^{-}\right)$and 4 -nitrophneol $\left(-\Delta_{-}\right)$by Fenton and photo-Fenton at 100 and $450 \mathrm{~W}$ UV light intensities. Experimental conditions: total solution volume $=4 \mathrm{~L} ; \mathrm{COD}=475 \mathrm{mgO}_{2} \mathrm{~L}^{-1}$ for all chemicals solutions: $T=25^{\circ} \mathrm{C} ; \mathrm{pH} 3.0 ;\left[\mathrm{Fe}^{2+}\right]=0.8 \mathrm{mM} ;\left[\mathrm{H}_{2} \mathrm{O}_{2}\right]=30 \mathrm{mM}$. Values are $m \pm s d$ $(n=3)$.

That is, $\mu_{\text {coDpartox }}$ was very high $(\approx 90 \%)$, while the achieved mineralization rates in the case of aromatics led to values $\approx 75 \%$. Assisting the Fenton reagent by UV radiation and increasing its power from 100 to $450 \mathrm{~W}$ improved much the mineralization of the compounds (Fig. 2) and progressively led to lower final $\mu_{\text {coDpartox values. Assist- }}$ ing the Fenton process with a $100 \mathrm{~W}$ UV lamp was enough to improve much the treatment of oxalic acid, resulting that $\mu_{\text {coDpartox }}$ was even lower $(<30 \%)$ than the values achieved for both aromatics $(<50 \%)$. Moreover, enhancing the power of the treatment using a 450 W UV lamp yielded $\mu$ coDpartox values $<25 \%$ for nitrophenol, phenol and oxalic acid, and even $<30 \%$ for EDTA, which was not perceptibly mineralized by the other two less powerful treatments. On the other hand, acetic acid was not perceptibly mineralized in general, so $\mu_{\text {conpartox }}$ was always $\approx 100 \%$. But, at the end of the $450 \mathrm{~W}$ photo-Fenton treatment of the acetic acid solution, a small perceptible amount of TOC was reduced, thus leading to a small reduction of $\mu_{\text {CoDpartox }}(\approx 95 \%)$. Finally, a $\mathrm{COD}_{\text {partox }} \approx 75-125 \mathrm{mgO}_{2} \mathrm{~L}^{-1}$ was achieved ( $\mu_{\text {coDpartox }} \approx 18-30 \%$, Fig. 8 ) at the end of the best treatment ( $450 \mathrm{~W}$ photo-Fenton) of the studied compounds.

In short, every organic chemical needs a different amount of $\mathrm{O}_{2}$ to complete its oxidation to carbon dioxide, water and other inorganic chemicals. Both aromatics theoretically generate $\approx 7 \mathrm{~mol}$ of COD for every mol of chemical. Since reaction aliphatics, such as oxalic and acetic acids, dominate the reaction products [17,30-32], the COD removal percentage was relatively high for both aromatic chemicals $(\approx 75 \%)$, whereas the degree of mineralization was relatively scarce $(\approx 20 \%)$ when applying the conventional Fenton treatment. To a first approximation, this could be explained by the much lower COD content produced per every mol of the byproducts generated by the aliphatics in comparison to parent aromatics. In fact, acetic acid was more resistant to oxidation than both phenolic substances when conventional Fenton was applied, showing only a $20 \%$ COD degradation and practically no mineralization (Figs. 1 and 2). Furthermore, HPLC measurements showed a very low breakdown level for this organic chemical, as the concentration of acetic acid in the treated solution remained close to the initial value after running the Fenton process for $60 \mathrm{~min}$. Oxalic acid and EDTA showed a very different behaviour as they quickly form complexes with $\mathrm{Fe}^{2+}$ (Fig. 4). Hence, there is a very low quantity of free $\mathrm{Fe}^{2+}$ in the solution prior to $\mathrm{H}_{2} \mathrm{O}_{2}$ addition $\left(<10 \mathrm{mg} \mathrm{L}^{-1}\right.$ for oxalic acid and $<2 \mathrm{mg} \mathrm{L}^{-1}$ for EDTA). The final reduction in the COD (time $=60 \mathrm{~min}$ ) was about a $5 \%$ for both chemicals (Fig. 1 ). They both showed an insignificant mineralization too (Fig. 2) in response to a conventional Fenton treatment. All the chemicals, with the exception of acetic acid, showed a better COD removal efficiency and mineralization when combining UV radiation with the Fenton's reagent (Figs. 1 and 2). Acetic acid showed very low molecule breakdown, resulting in an approximately $20 \%$ final removal of the COD and no mineralization for all the tested treatments. In conclusion, all the efficiency of all the treatments was performed via partial oxidation. This behaviour could be related to the formation of very stable Fe(III)-complexes under the chosen reaction conditions. These iron complexes could not be broken even by the $450 \mathrm{~W}$ UV lamp.

Oxalic acid and EDTA showed similar behaviours when comparing both Fenton and photo-Fenton treatments (Figs. 1 and 2), although treatment results in terms of reduction in both COD and TOC were higher for oxalic acid in all the cases. Oxalic acid showed from an $8 \%$ COD removal, when applying the conventional Fenton process, to around $20 \%$ if the $100 \mathrm{~W}$ photo-Fenton was performed. Finally, almost a $100 \%$ reduction in the COD was obtained when the $450 \mathrm{~W}$ photo-Fenton treatment was applied. Mineralization percentages rose correspondingly from insignificant, when applying the conventional Fenton treatment, to about $20 \%$ and $80 \%$ when applying 100 and $450 \mathrm{~W}$ photo-Fenton treatments, respectively (Figs, 1 and 2). This is in agreement with the work presented by Aplin et al. [52], who found that the light intensity had a large effect on the rate of oxalates degradation. In the absence of light they found no degradation of oxalates, and the COD removal was much faster when a neutral density filter was not used, so increasing the light intensity up to a $150 \%$. The photolysis of $\mathrm{Fe}$ (III)-oxalate complexes was found to be the rate limiting reaction and were relatively unreactive to hydroxyl radical. Several authors have used this iron oxalate property for the treatment of numerous pollutants in water [53-55].

Similarly, EDTA exhibited an $8 \%$ reduction in the COD and no mineralization when conventional Fenton was applied. In contrast, the irradiation of UV light improved the treatment of EDTA up to a $20 \%$ in terms of COD removal, but still no mineralization was achieved, when using the $100 \mathrm{~W}$ UV lamp; and up to a $60 \%$ COD removal and a $40 \%$ TOC removal was yielded by the $450 \mathrm{~W}$ photoFenton treatment. But no additional degradation was possible over the first $20 \mathrm{~min}$ of this treatment of EDTA. All the hydrogen per- 
oxide was completely consumed (Fig. 6). Moreover, at this time $\left(t=20\right.$ min), EDTA treatments had consumed $\mathrm{H}_{2} \mathrm{O}_{2}$ faster than in the corresponding oxalic acid ones. These results are related to the reported light-sensitive characteristics of Fe-EDTA complexes and EDTA degradation itself. Particularly, some authors showed that Fe-EDTA is photo-degradable, or that EDTA removal by photooxidation is improved in the presence of iron [56-58]. Moreover, EDTA's binding strength is considered as light sensitive for some metals, iron included [59]. On the other hand. EDTA itself is considered as a recalcitrant compound to both biological and chemical processes during sewage treatment [56].

Results clearly show that degradation of oxalic acid, EDTA, phenol and 4-nitrophenol depends on the UV light intensity applied in their photo-Fenton treatment. As showed in Figs. 1 and 2, the influence on the degree of mineralization was more significant than on the removal of COD. For instance, the treatment of aromatics by the conventional Fenton process did not produce great mineralization results (TOC removal $\approx 20 \%$ ) but a high COD removal $(\approx 80 \%$ ); while increases in the reduction in the COD up to a $95 \%$ and a $99 \%$ in the presence of 100 and $450 \mathrm{~W}$ UV lamps led to a $50 \%$ and an $80 \%$ TOC removals, respectively. Phenol and 4-nitrophenol were broken down during the first $5 \mathrm{~min}$ of the treatments, producing carboxylates as byproducts. The presence of UV light also enhanced the degradation of the phenolic compounds, although not so much than in the cases of EDTA or oxalic acid. Finally, acetic acid was negligibly responsive to the photo-assisted Fenton processes.

The extent of $\mathrm{Fe}^{3+}$ complex formation for 4-nitrophenol and phenol are of the same order of magnitude (Table 1) and the difference in the degree of degradation and mineralization by the Fenton processes were insignificant, although mineralization rates resulted even higher for nitrophenol in the presence of light (Table 2 ). The fast hydroxyl radical attack to the aromatic ring $(<5 \mathrm{~min})$ produce a great reduction in the $\operatorname{COD}(\approx 80 \%)$, yielding aliphatic chemicals as byproducts, such as oxalic and acetic acids $[17,30-32]$. The further oxidation of these byproducts does not yield a relative great increase of the reduction in the COD, but generates up to an $80 \%$ TOC removal when applying the $450 \mathrm{~W}$ photo-Fenton treatment. Phenol and 4-nitrophenol were also the fastest $\mathrm{H}_{2} \mathrm{O}_{2}$ consuming species under all circumstances (Fig. 6). In fact. Trapido and Kallas [60] found that the degradation rate of 4-nitrophenol was strongly dependent on the concentrations of hydrogen peroxide and $\mathrm{Fe}^{2+}$. This could be explained by the weak complex formation with $\mathrm{Fe}^{2+}$, so ferrous ion regeneration could also be supposed to happen in the greatest quantities when treating aromatics by photo-Fenton processes. That is, $\mathrm{Fe}^{2+}$ regeneration was also improved by UV irradiation. At the onset of the reaction, there was sufficient free $\mathrm{Fe}^{2+}$ to generate enough hydroxyl radjcals to break down the cyclic structure of the phenolic compounds. The relatively lower concentrations of carboxylates as byproducts, in comparison to equal initial COD aliphatic compounds solutions, may have led to more free ferrous ions in the solution due to the presence of UV irradiation.

\section{Conclusions}

It has been clearly shown that both aromatic and aliphatic structures and stability constants of iron (ferrous and ferric) complexes formation are related to the effectiveness of the Fenton and photoFenton processes for the treatment of organic chemicals. Aromatics are easily broken down to aliphatics by Fenton's reagent alone. With the exception of acetic acid, reduction in the COD and mineralization, in terms of both final TOC removal and pseudo-first-order rate constants, resulted dependant on the UV light intensity. The reduction in the COD achieved for oxalic acid, phenol and nitrophenol in the best photo-Fenton treatment ( 450 WUV lamp) was almost total
(95.99\%), while only an $80 \%$ of reduction in the TOC was achieved. In the case of EDTA $60 \%$ COD and $40 \%$ TOC removals were achieved as best results. In short, a final $\mathrm{COD}_{\text {partox }} \approx 75-125 \mathrm{mgO}_{2} \mathrm{~L}^{-1}$ remained at the end of the best photo-Fenton treatment of these chemicals. This means that $\approx 18-30 \%$ of the reduction in the COD was not performed via mineralization. Acetic acid showed no significant differences in its COD removal and mineralization when applying Fenton or photo-Fenton processes, that is, a 20\% COD removal and insignificant mineralization. Therefore, all the COD was removed via partial oxidation.

\section{Acknowledgments}

This research was developed in the framework of projects GR/AMB/0269/2004 and M0500204133 funded by Universidad Politécnica de Madrid and Comunidad Autónoma de Madrid (Spain), who also granted Daphne Hermosilla a scholarship to study at the University of Delaware. The authors wish to thank Sammy Lin for his help with the HPLC measurements and Michael Davidson for technical support.

\section{References}

I1] S. Esplugas, J. Giménez, S. Contreras, E. Pascual, M. Rodríguez, Water Res. 36 (2002) 1034-1042

12| W.H. Glaze, J.W. Kang. D.H. Chapin, Ozone-Sci. Eng. 9 (1987) 335-352.

|3| R.J. Bigda, Chem. Eng. Prog. 91 (1995) 62-66.

14| H. Zliang. H.J. Clioi, C.P. Huang, J. Hazard. Mater, 125 (2005) 166-174.

I5I H.J.H. Fenton, J. Chem. Soc. 65 (1894) 894-910.

|6] F. Hatber, J.]. We iss, J. Am. Cliem. Soc. 45 (1934) 338-351.

|7| Y.W. Kang, K. Hwang, Water Res, 34 (2000) $2786-2790$.

|8| E. Neyens, J. Baeyens, J. Hazard, Mater, B 98 (2003) 33-50.

|9| C. Walling, S. Kato, J. Am. Chem. Soc. 93 (1971) 4275-4281.

I10| N. Kang. D.S. Lee, J. Yoon Chemosphere 47 (2002) 915-924.

|11| V. Kavitha, K. Palanivelu, Chemosphere 55 (2004) 1235-1243.

$112 \mid$ V. Kavitha, K. Palanivelu, J. Environ. Sci. Health A 38 (2003) 1215-1231.

|13| M. Pérez-Moya, M. Graells, L.J. del Valle, E, Centelles, H.D. Mansilla, Catal. Today $124(2007) 163-171$.

|14| S.F. Kang, T.H. Wang. Y.H. Lin,J. Environ. Sci. Health A 34 (1999) 935-950.

|15| E. Lipczynska-kochany, Environ. Technol. 12 (1991) 87-92.

|16| M.L. Rodríguez, V.I. Tìmokhin, S. Contreras, E. Chamarro, S. Esplugas, Adv. Enviroil. Res. 7 (2003) 583-595.

|17| V. Kavitha, K. Palanivelu, J. Photochem, Photobiol, A 170 (2005) 83-95.

|18| G. Ghiselli, W.F. Jardim, M.I. Litter, H.D. Mansilla, J. Photochem. Photobiol. A 167 (2004) 59-67.

|19| K. Pirkanniemi, S. Metsärinne, M. Sillanpää, J. Hazard. Mater. 147 (2007) 556-561.

|20| W.G. Kuo, Water Res. 26 (1992) 881-886.

211 E.C. Catalkaya, F. Kargi, J. Hazard. Mater. $139(2007) 244-253$.

|22| D. Hetmosilla, M. Cottijo. C.P. Huang. Sci. Total Enviton. 407 (2009) 3473-3481.

23| A. Sinha, S. Chakrabarti, B. Chaudhuri, S. Bhattacharjee, P. Ray, Ind. Eng. Chem. Res. 46(2007) 3101-3107.

|24| B.C. Faust, J. Hoigne, At mos, Erviron. A 24 (1990) 79-89.

125| A. SafarzadehAmiri, J.R. Bolton, S.R. Cater, Water Res. 31 ( 1997 ) 787-798.

|26| U. Bali, E.C. Catalkaya, F. Sengul, J. Envicon. Sci. Health A 38 (2003) 2259-2275.

127| M.Y. Ghaly, G. Härtel, R. Mayer, R. Haseneder, Waste Manage. 21 (2001) 41-47.

|28| E. Brillas, M.A. Baños, J.A. Garrido, Electrochim. Acta 48 (2003) 1697-1705.

29] A.M. Amat, A. Arques, F. Lopez, M.A. Miranda, Solat Enelgy 79 (2005) 393-401.

|30| J.A. Zazo, J.A. Casas, A.F. Mohedano, M.A. Gilarranz, J.J. Rodrïguez, Environ. Scì. Teclinol. 39 (2005) 9295-9302.

131] T. Turan-Ertas, M.D. Curol, Chemosphere 47 (2002) 293-301.

1321 M.A. Oturan, J. Peiroten, P. Chart rin, A.J. Acher, Environ. Sci. Technol. 34 (2000) 3474-3479.

133| M.A. Oturan, M. Pímentel, N. Oturan, I. Sìrés, Electrochím. Acta 54 (2008) $173-182$.

|34| C.H. Lì, Y.H. Huang, H.T.Chen, M.C. Lu, J.Adv. Oxìd. Technol. 10(2007) 430-434.

|35| K. Hirano, T. Yamada, Y. Asami, R. Takagi, I. Izumi, Denki Kagaku 52 (1984) $253-254$.

|36| N. Quici, M.E. Morgada, G. Piperata, P. Babay, R.T. Gettar, M.I. Litter, Catal. Today 101 (2005) 253-260.

|37| B, Bayarti, 0. González, M.I, Maldonado, J. Jiménez, S. Esplugas, J. Solar Energy Eng. $129(2007) 60-67$

[38| A, Di Paola, V. Augugliaro, L Palmisano, G. Pantaleo, E. Savinov, J. Photochem. Photobiol. A 155 (2003) 207-214.

|39| H,D. Mansilla, C. Btavo, R, Ferreyra, M,I. Litter, W,F, Jatdim, C. Lizama, J. Freet, J Fernández, I. Pliotochem. Plotobiol. A 181 (2006) 188-194.

I40| J. Araña, O. González, J.M. Doña, J.A. Herrera, C. Garriga, J. Pérez, M.C. Hidalgo, J.A. Navio-Santos, J. Mol. Catal. A 197 (2003) 157-171.

I41| F. Vogel, J. Harf, A. Hug, P.R. von Rohr, Water Res. 34 (2000) $2689-2702$. 
142| M. Catbajo, F.J. Beltrán, 0. Gimeno, B. Acedo, F.J. Rivas, Appl. Catal. B 74 (2007) $203-210$

|43| A,E. Martell, R.M. Smith, Critical Stability Constants, Plenum Ptess, New York, 1989.

$|44|$ W. Stumm, J.J. Morgan (Eds. ), Aquatic Chemistry, John Wiley \& Sons, New York, 1996.

145I APHA AWWA, WPC.F (Eds.), Standard Methods for the Examination of Water and Wastewater, APHA/AWWAJWPCF, Washington, DC, 1989.

|46| I. Talinli, G.K. Andecsoin, Water Res. 26 (1992) 107-110.

147| Y.W. Kang, M. Cho, K. Hwang, Water Res. 33 (1999) 1247-1251.

|48| H. Pobiner, Allal. Cliem. 33 (1961) 1423-1428.

|49| H. Tamura, K. Goto, T. Yotsuyanagi, M. Nagayama, Talanta 21 (1974) 314-318.

|50| Y. Alegría, F. Liendo, O. Nuñez, Arkivoc 10 (2003) 538-549.
[51] J.]. Pignatello, E. Oliveros, A, MacKay, Crit, Rev. Enviton, Sci. Teclinol, 36 (2006) $1-84$.

[52] R. Aplin, A.J. Feitz, T.D. Waite, Water Sci, Teclinol, 44 (2001) 23-30.

[53] Y, Chen, F, Wu, Y, Lin, N. Deng, N. Bazhin, E. Glebov, J. Hazard. Mater. 148 (2007) $360-365$.

[54] F.B. Li, X.Z, Li, C.S. Liu, X.M. Li, T.X. Liu, Ind, Eng. Chem. Res. 46 (2007) 781-787.

[55] A. Zhou, F. Wu, N. Deng, Chemosphere 57 (2004) 283-291.

[56] F.K. Guenter, G. Walter, Water Res. 30 ( 1996) 122-134.

[57] C.A. Emilio, W.F. Jardim, M.I. Litter, H.D. Mansilla, J. Photochem. Photobiol. A $151(2002) 121-127$

[58] P. Kocot, A. Karocki, Z. Stasicka, J. Photochem. Photobiol. A 179 (2006) 176-183.

[59] N. Kelton, L.A. Molot, P.J. Dillon, Aquat. Sci. 69 (2007) $86-95$.

[60] M. Trapido, J. Kallas, Environ. Technol. 21 (2000) 799-808. 